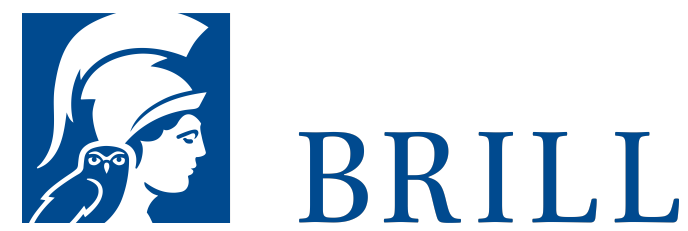

\title{
Naturgesetze in einer kausalen Welt
}

Author: Andreas Bartels

Wie können Naturgesetze, die bestimmen, wie Objekte der Natur sich verhalten, selbst als Objekte der Natur verstanden werden? Die Antwort, die sich aus der Analyse gegenwärtiger Naturgesetztheorien herausschält, lautet: Naturgesetze verdanken sich der kausalen Struktur unserer Welt. Sie drücken die kausale Wirksamkeit fundamentaler Eigenschaften der Natur aus. Im Unterschied zu konkurrierenden Theorien wird diese Antwort der Tatsache gerecht, dass Naturgesetze den Verlauf des Naturgeschehens bestimmen, ohne auf die starke Annahme notwendig wirkender Kräfte zurückgreifen zu müssen. Der Zwang, den Naturgesetze ausüben, spiegelt stattdessen eine grundlegende faktische Beschaffenheit unserer Welt wider: Fundamentale Eigenschaften wie Ladung oder Masse üben ihre Wirksamkeit ungehindert aus, ohne sich gegenseitig zu beeinflussen. Die >Notwendigkeit $<$, die Naturgesetze vermitteln, ist daher mit ihrer metaphysischen Kontingenz, der Möglichkeit anderer Naturgesetz-Welten, vereinbar. Die vorgeschlagene Theorie verknüpft Naturgesetze und Kausalität auf neue Weise: Nur in einer zeitlich asymmetrischen Welt kann es Kausalität geben, und nur in einer kausalen Welt können fundamentale Eigenschaften jene asymmetrischen Relationen ausbilden, die wir Naturgesetze nennen.

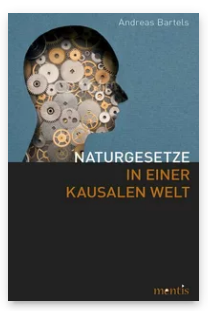

Pages: 253

Seiten

Language:

German

Subjects:

General,

Philosophy

Publisher: Brill | mentis

E-Book (PDF)

Released online: 28 Sep 2015

ISBN: 978-3-

95743-867-6

List price

Paperback

Publication date: 28 Sep 2015

ISBN: 978-3-

95743-025-O

List price 
For more information see brill.com

Order information: Order online at brill.com +44330 333 0049 | customerservices@brill.com Submission information: brill.com/authors

Titles published by Brill | Fink, Brill | mentis or Brill | Schöningh: +49(o)715413279216| brill@brocom.de 